\title{
Sliding Wear Evaluation of Hot Isostatically Pressed (HIPed) Thermal Spray Cermet Coatings
}

\author{
V. Stoica, R. Ahmed \\ Heriot Watt University, School of EPS, EH14 4AS, Edinburgh, United Kingdom \\ T. Itsukaichi \\ Fujimi Inc., Kakamigahara, Japan \\ S. Tobe \\ Ashikaga Institute of Technology, Ashikagashi, Japan \\ M. Escribano \\ Universität Stuttgart, Stuttgart, Germany
}

\begin{abstract}
The aim of this preliminary investigation was to ascertain the synergetic potential of two process technologies of thermally spraying and HIPing (Hot Isostatic Pressing) for tribological applications and address the key design factors, which need to be considered for successful applications of HIPed thermal spray WC-NiCrBSi coatings. The relative performance of the as-sprayed and hot isostatically pressed WC-NiCrBSi functionally graded coatings was investigated in sliding wear conditions. Results indicate that HIPing post-treatment can improve the sliding wear resistance of WC-NiCrBSi coatings. These coatings were deposited by a High Velocity Oxy-Fuel JP5000 system and HIPing process was carried out at two different temperatures of $850^{\circ} \mathrm{C}$ and $1200^{\circ} \mathrm{C}$. This study shows that un-capsulated HIPing can be successfully applied to functionally graded WC-NiCrBSi coatings, which has economical as well as technical incentives for industrial applications. Sliding wear tests were carried out using a high frequency reciprocating ball on plate rig using steel and ceramic balls. Results are discussed in terms of powder manufacture method, microstructural investigations, phase transformation, mechanical properties and residual stress investigations. Phase analysis by x-ray diffraction revealed transformations, which altered the phase composition such as the elimination of secondary phase $\mathrm{W}_{2} \mathrm{C}$ and metallic $\mathrm{W}$ and the formation of new phases containing $\mathrm{Ni}, \mathrm{Si}$ and $\mathrm{B}$ after the post-treatment. The measurements of hardness, Young's modulus and residual stress indicate that substantial improvements can be achieved due to simultaneous application of temperature and pressure during the HIPing post-treatment. Hardness and Young's modulus measured by indentation method, increased after the HIPing process due to the transformations in the morphology and phase composition
\end{abstract}

of the coatings. The residual stress evaluations by $\sin ^{2} \Psi$ technique using synchrotron $\mathrm{x}$-ray diffraction showed a relaxation of residual stress fields in the coating with increasing temperature of the HIPing process.

\section{Introduction}

Post-treatments of thermal spray coatings have proved their potential providing a higher corrosion and wear resistance. Previous post-treatment studies have concentrated on three main areas i.e. austempering/annealing, laser melting and Hot Isostatic Pressure (HIP). Promotion of metallurgical bonding at splat/splat and splat/substrate interface to improve the adhesive and cohesive strength, elimination of coating porosity to avoid stress concentrations, phase transformation from amorphous to crystalline, generation of uniform compressive stress and attenuation of coating anisotropy to obtain near homogeneous material properties are some of the desired post-treatment improvements, when a high degree of resistance to fatigue, impact loading, delamination and corrosive/erosive/abrasive wear is required.

Hot Isostatic Pressing as a post-treatment of thermal sprayed coatings is a technology that was successfully applied in tribological applications [1-3]. The simultaneous application of high temperature and pressure promotes an attractive combination of material properties through changes in coating microstructure, beneficial phase transformations and reduction in porosity levels [1-6]. 
Table 1: Properties of agglomerated and sintered WCNiCrBSi powders.

\begin{tabular}{|c|c|c|}
\hline Powder & $\begin{array}{c}90 \% \text { WC-10\%Alloy } \\
(\text { WC10X) }\end{array}$ & $\begin{array}{c}60 \% \text { WC-40\%Alloy } \\
\text { (WC40X) }\end{array}$ \\
\hline $\begin{array}{l}\text { Particle size } \\
\text { distribution, } \mu \mathrm{m}\end{array}$ & $-45+15$ & $-45+20$ \\
\hline $\begin{array}{l}\text { Apparent density, } \\
\mathrm{g} / \mathrm{cm}^{3}\end{array}$ & 4.42 & 3.51 \\
\hline $\mathrm{WC}$ - grain size, $\mu \mathrm{m}$ & $3-4$ & $3-4$ \\
\hline Powder production & Aggl. and sint. & Aggl. and sint. \\
\hline Powder shape & spherical & spherical \\
\hline Alloy composition & $\begin{array}{c}\text { Ni:Bal., Cr:7.6\%, } \\
\text { Si:3.6\%, Fe: } 2.4 \%, \text { B: } \\
\text { 1.6\%, C: } 0.25 \%\end{array}$ & $\begin{array}{c}\text { Ni:Bal., Cr:7.6\%, } \\
\text { Si:3.6\%, Fe: } 2.4 \%, \text { B: } \\
\text { 1.6\%, C: } 0.25 \%\end{array}$ \\
\hline
\end{tabular}

Table 3: Steel and ceramic ball properties used in high frequency reciprocating ball on disc tribometer.

\begin{tabular}{|l|c|c|}
\hline & $440 \mathrm{C}$ steel & $\mathrm{Si}_{3} \mathrm{~N}_{4}$ \\
\hline Diameter, $\mathrm{mm}$ & 12.7 & 12.7 \\
\hline Density, $\mathrm{kg} / \mathrm{m}^{3}$ & 3165 & 7769 \\
\hline Weight, $\mathrm{g}$ & $\sim 3$ & $\sim 8$ \\
\hline Average roughness $\mathrm{R}_{\mathrm{a}}, \mu \mathrm{m}$ & 0.015 & 0.013 \\
\hline Hardness $(\mathrm{HV} 0.1), \mathrm{kg} / \mathrm{mm}^{2}$ & 820 & 1580 \\
\hline
\end{tabular}

It is anticipated that advantages of the above-mentioned improvements will offset the cost of HIPing process in industrial applications.

This paper reports the effect of HIPing process on the sliding wear resistance of the WC-Ni based alloy coatings. Results are discussed in terms of powder manufacture method, microstructural investigations, phase transformation, mechanical properties and residual stress investigations.

\section{Experimental Procedure}

\section{Material Selection}

The powders used in this study were agglomerated and sintered tungsten carbide - nickel based alloy. These powders were specifically manufactured by pre-alloying using agglomerated and sintered route in two different compositions shown in Table 1. This table also summarizes the main characteristics of these powders.

For the rest of this paper WC10X or WC40X will be used as denomination when referring to the powders or coating layers.
Table 2: HVOF (JP5000) spray parameters.

\begin{tabular}{|l|c|}
\hline Spray system & JP-5000 \\
\hline Oxygen flow & $89311 / \mathrm{min}$ \\
\hline Fuel (kerosene) flow & $0.3211 / \mathrm{min}$ \\
\hline Spraying distance & $380 \mathrm{~mm}$ \\
\hline Gun barrel length & $101.5 \mathrm{~mm}$ \\
\hline Spraying rate & $50 \mathrm{~g} / \mathrm{min}$ \\
\hline
\end{tabular}

Coating Production and Post-Treatment

Functionally graded coatings were sprayed on the shot blasted surface of $31 \mathrm{~mm}$ diameter, 440-C steel discs by the High Velocity Oxy-Fuel process using a JP5000 system. Coating deposition parameters are listed in Table 2. WC40X powder was sprayed on the steel substrate until an average coating thickness of $100 \mu \mathrm{m}$ was attained. Onto this, $400 \mu \mathrm{m}$ thick WC10X coating was applied as shown in Fig. 1.

The HIPing treatment was carried out at two different temperatures of $850^{\circ} \mathrm{C}$ and $1200^{\circ} \mathrm{C}$ at a pressure of $150 \mathrm{MPa}$ in argon environment. The coatings were not encapsulated and kept at constant HIPing temperature in the furnace for 60 minutes.

Coating Characterisation

The X-ray diffraction (XRD) analysis was conducted using a D500 diffractometer operating at $40 \mathrm{kV}$ and $20 \mathrm{~mA}$ in order to investigate the phase transformations that occurred during coating deposition and post-treatment. $\mathrm{CuK} \alpha$ radiation was used and the samples were run at $2 \theta$ from $10^{\circ}$ to $90^{\circ}$ with a step size of $0.02^{\circ}(2 \theta)$ and a time of $2 \mathrm{~s} / \mathrm{step}$.

The powder and coating microstructures were evaluated by Scanning Electron Microscopy (SEM) using conventional

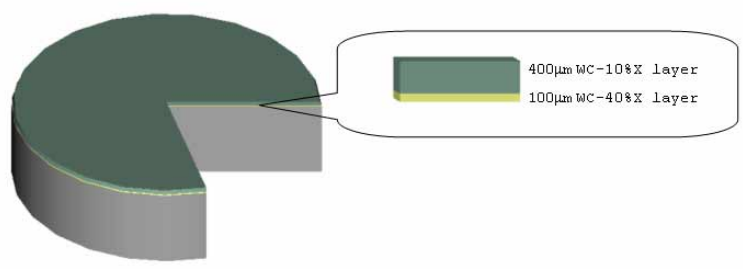

Figure 1: Functionally graded coating system containing a 100 and $400 \mu \mathrm{m}$ layer of $\mathrm{WC}-40 \mathrm{NiCrBSi}$ and $\mathrm{WC}-10 \mathrm{NiCrBSi}$, respectively. 
imaging with secondary electrons. Hardness and elastic modulus measurements were performed on the metallographic prepared samples on the surface and on the coating cross section under a load of $500 \mathrm{mN}$. The load was applied for twenty seconds and maintained for five seconds. Ten measurements were performed on each coating surface and thirty on each cross section, which were distributed in 3 lines of ten measurements points each, one at $50 \mu \mathrm{m}, 150 \mu \mathrm{m}$ and $250 \mu \mathrm{m}$, respectively from the coating's surfaces. A distance of $100 \mu \mathrm{m}$ between indentations was ensured to eliminate stressfield effect from nearby indentations. Young's modulus was measured using real time displacement of force indentation curve during a hardness test. A complete description of the measurement procedures can be found in [8].

Measurements of the residual stress distribution within the assprayed and HIPed coatings were performed using x-ray synchrotron radiations. The $\sin ^{2} \psi$ method was applied with three $\psi$ angles between 7 and $9^{\circ}$ at $25 \mathrm{kV}$ and between 12 and $14^{\circ}$ at $15 \mathrm{kV}$. The shift of the diffraction peak was recorded and the magnitude of the shift related to the magnitude of the residual stress through the slope of the $2 \theta-\sin ^{2} \psi$ plot. A similar approach was used to calculate the residual strain. The peak position was determined using the peak centre of gravity.

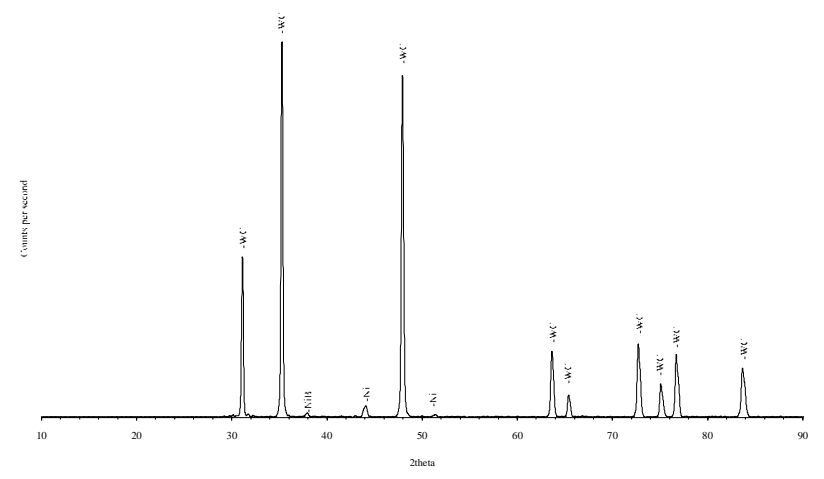

a) WC10X powder

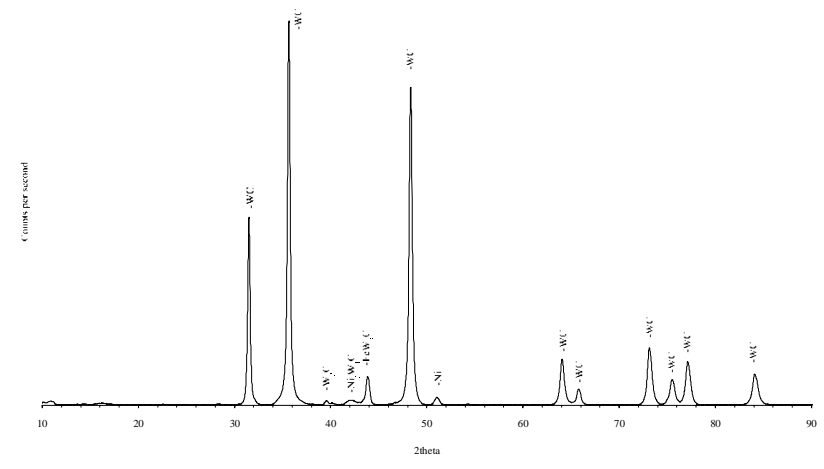

c) HIPed at $850^{\circ} \mathrm{C}$ coating

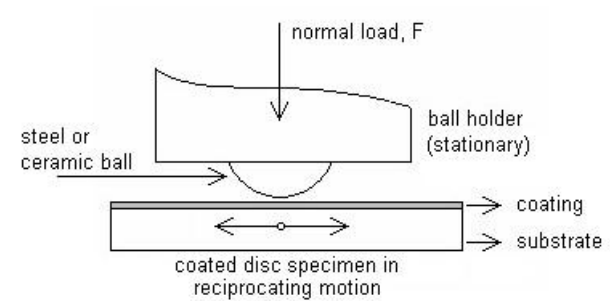

Figure 2: High frequency reciprocating ball on disk tribometer.

\section{$\underline{\text { Tribological Testing }}$}

Sliding wear tests were carried out using a reciprocating ballon-plate tribometer, instrumented to measure the frictional force via a load cell (Fig. 2). The counterbodies were 440C steel and silicon nitride ceramic balls whose properties are listed in Table 3 . The coatings were ground and polished to produce a surface roughness $\left(R_{a}\right)$ of $0.04 \mu \mathrm{m}$. In the setup show in Fig. 2 the upper ball bearing the normal load is stationary, while the coated disc has a sliding speed of $0.012 \mathrm{~m} / \mathrm{s}$ at the centre of the wear scar. Before each test, the coatings and balls

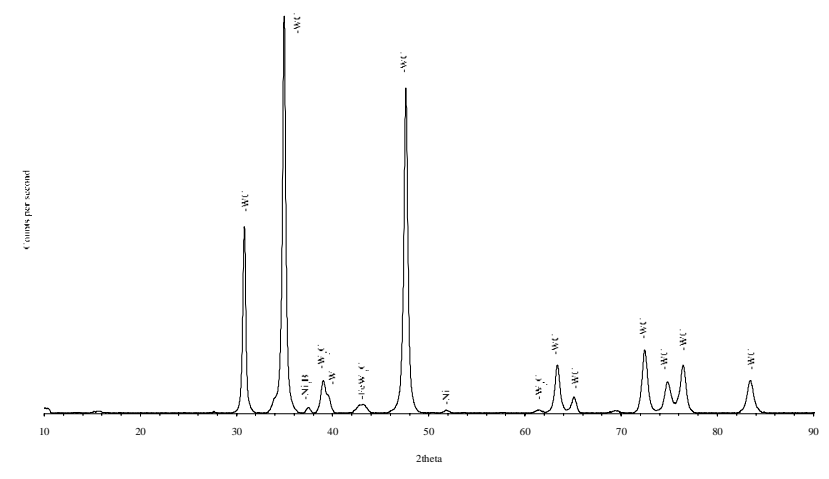

b) as-sprayed coating

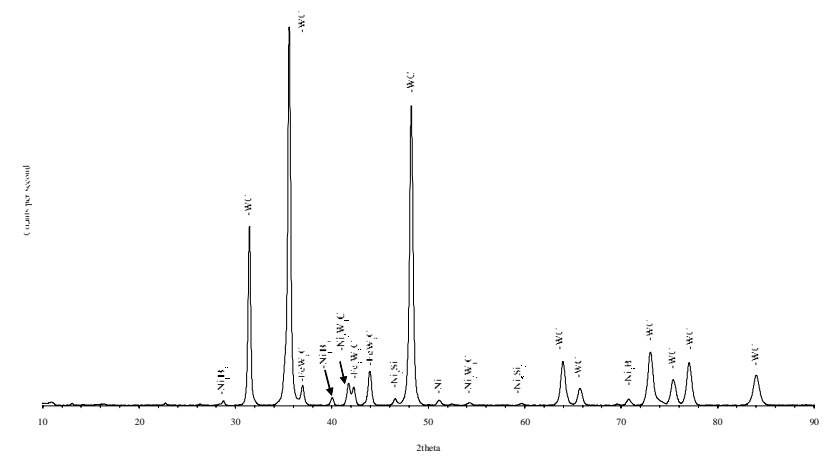

d) HIPed at $1200^{\circ} \mathrm{C}$ coating

Figure 3: XRD patterns of WCIOX powder, as-sprayed and HIPed coatings. 


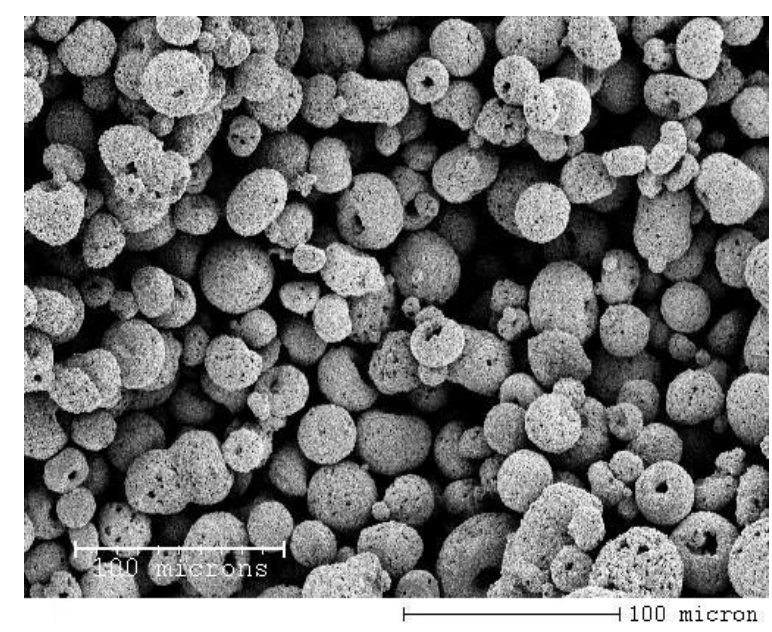

a) WC10X powder

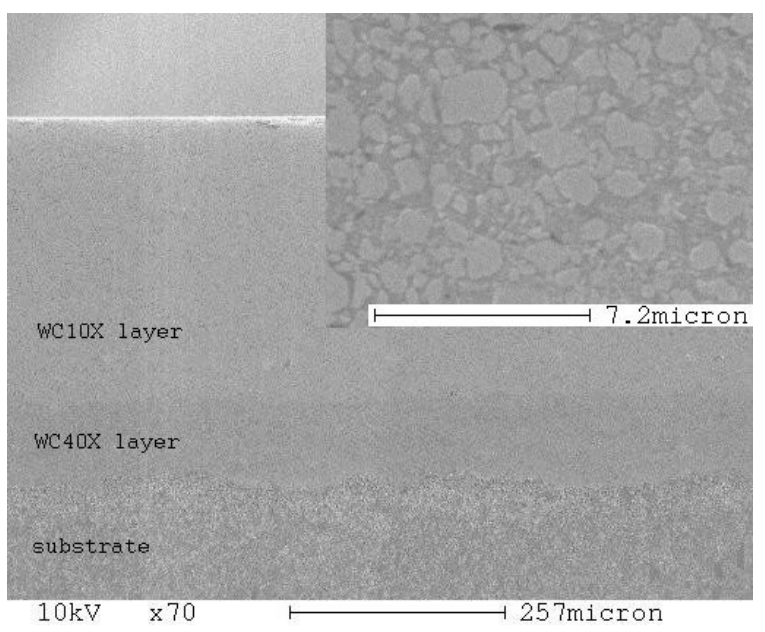

c) HIPed at $850^{\circ} \mathrm{C}$ coating

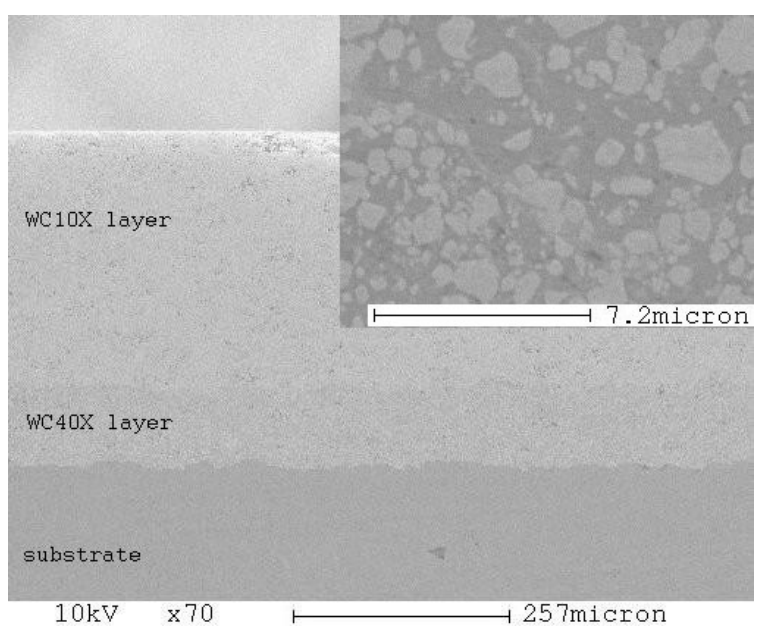

b) as-sprayed coating

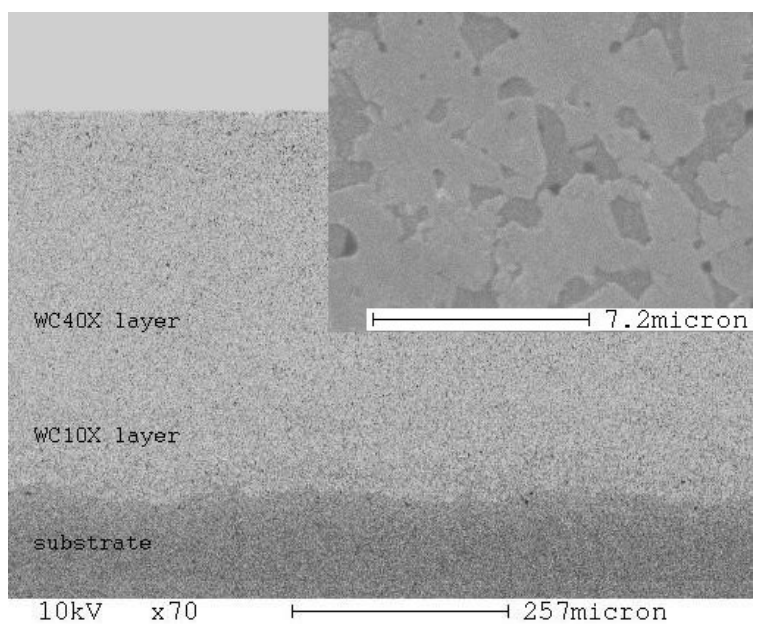

d) HIPed at $1200^{\circ} \mathrm{C}$ coating

Figure 4: Low magnification scanning electron micrographs of the powder, as-sprayed and HIPed coatings (the inlets are high magnification micrographs of WC40X layer of the coatings corresponding to low magnification micrographs)

were ultrasonically cleaned in acetone for 5 minutes to remove any contaminants and grease, dried in air and weighed. The tests were performed in dry contact conditions at ambient temperature and humidity under $4 \mathrm{~kg}$, which corresponds to a stress in the range of $2.24-2.38 \mathrm{GPa}$ and $2.63-2.83 \mathrm{GPa}$ for contact against steel and ceramic balls, respectively.

The coating wear scars were examined using Zygo NewView 5000 interferometer, which provided the volume loss of the material for each wear scar. The volume loss of the ball was evaluated using an optical microscope, which allowed the precise measurement of the ball wear scar diameter. Moreover, using the diameter of the sphere segment removed during the test, the ball volume loss $(V)$ was calculated as follows:
$V=\pi H^{2}(3 R-H) / 3$ where $H=R-\left(R^{2}-r^{2}\right)^{1 / 2}$ and " $R$ " and " $r$ " are the ball radius and ball-wear-scar radius, respectively.

\section{Experimental Results}

Microstructural Analysis

X-Ray spectras of both powders indicate that their composition comprises of high quantity of mono tungsten carbide (WC) and certain amounts of metallic nickel and nickel boride. Deposition of these powders under the conditions listed in Table 2 led to the formation of secondary phase tungsten carbide $\left(\mathrm{W}_{2} \mathrm{C}\right)$, metallic tungsten $(\mathrm{W})$ and reaction between nickel and silicon. Part of the carbon which resulted from the decomposition of mono tungsten carbide reacted with oxygen during deposition and part is found in 
complex carbide $\mathrm{FeW}_{3} \mathrm{C}$. Figure $3 \mathrm{c}$ exhibits the phase composition of the coating which was HIPed at $850^{\circ} \mathrm{C}$. It can be observed that the partial disappearance of secondary phases $\mathrm{W}_{2} \mathrm{C}$ and metallic $\mathrm{W}$, the formation of carbide phases containing either $\mathrm{Ni}$ or $\mathrm{Fe}$, and also the occurrence of Ni solid solution resulted from this post-treatment. X-ray spectra of the coating HIPed at $1200^{\circ} \mathrm{C}$ shows further increase in the number of complex carbide phases and the occurrence of new phases as a result of reactions between $\mathrm{Ni}$ and $\mathrm{B}$ or $\mathrm{N}$ and $\mathrm{Si}$.

SEM micrographs of powders, as-sprayed and HIPed coatings are presented in Fig. 4. The powders exhibit spherical shape typical of agglomerated and sintered powders. As seen in Fig. $4 \mathrm{c}$, the coating $\mathrm{HIPed}$ at $850^{\circ} \mathrm{C}$ does not allow for clear delimitation of the first deposited layer (WC40X). This became more obvious in the coating $\mathrm{HIPed}$ at $1200^{\circ} \mathrm{C}$ where the borderline between the first layer (WC40X) and the substrate or the upper layer (WC10X) almost disappeared. Higher magnification SEM micrographs were included as insets in the top right of the corresponding low magnification images. HIPed coatings indicate a transformation in the shape of tungsten carbide grains from rounded shape of WC grains in as-sprayed coatings to angular in shape grains in HIPed coatings. Another observation was that in the HIPed coatings, the WC grains have the tendency to form islands of carbide grains.

Mechanical Testing Results

The results of the microhardness measurements are displayed in Fig. 5, showing measurements taken on the coating surface and the coating cross section. Both HIPed coatings are harder than the as-sprayed coating, on the surface and through thickness. The hardness measured on the cross section of the as-sprayed and HIPed at $850^{\circ} \mathrm{C}$ coatings have the same trend. It decreases between 50 and $150 \mu \mathrm{m}$ remaining almost constant for the next $100 \mu \mathrm{m}$. Thus these coatings are hard on the surface and in near-surface regions and more ductile below surface. Also the difference in the hardness between these two coatings remains about $100 \mathrm{~N} / \mathrm{mm}^{2}$ for all measurements performed. A rather oposite trend can be observed on the hardness measured on coating HIPed at $1200^{\circ} \mathrm{C}$. It has a very small decrease between 50 and $150 \mu \mathrm{m}$ followed by an increase to around $1200 \mathrm{~N} / \mathrm{mm}^{2}$.

Elastic modulus results are shown in Fig. 6. This graph indicate a higher elastic modulus of both HIPed coatings compared with the as-sprayed coating. Although the coating HIPed at $1200^{\circ} \mathrm{C}$ has higher modulus, the low gradient displayed by the coating HIPed at $850^{\circ} \mathrm{C}$ is very important and will be addressed in the Discussion section.

Figure 7 shows the results of residual stress measurements at two different radiation energies which correspond to different penetration depths. For all coatings tensile residual stresses were measured. The magnitude of these tensile stresses increases as the penetration depth increases reaching a maximum of around $2550 \mathrm{MPa}$ at a radiation energy of $25 \mathrm{kV}$.
The general tendency of the residual stresses, regardless the penetration depth, is to increase from the value found on assprayed coating for both HIPed coatings. However it seems

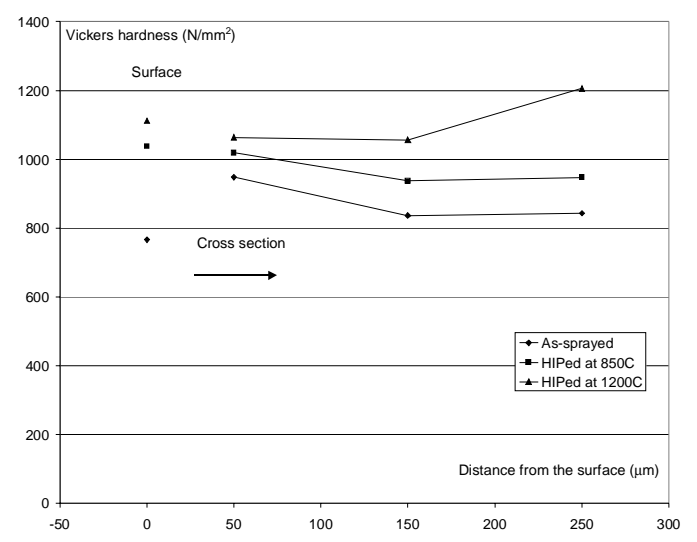

Figure 5: Vickers microhardness results on the coating surface and cross section of the as-sprayed and HIPed coatings.

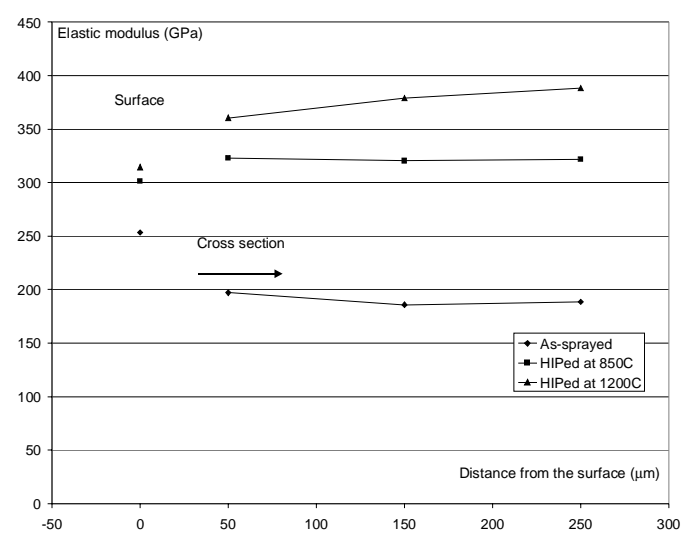

Figure 6: Elastic modulus results on the coating surface and cross section of the as-sprayed and HIPed coatings.

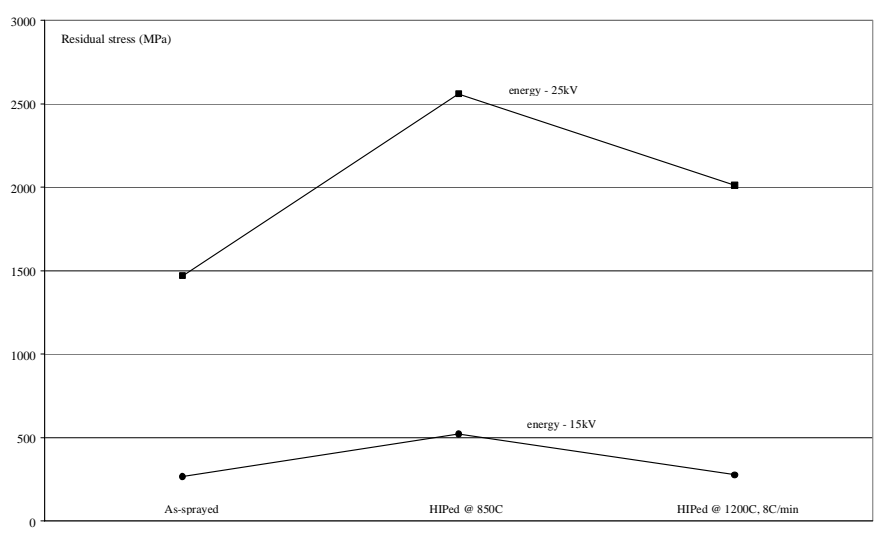

Figure 7: Residual stress results. 
that the increase of these stresses is less at low penetration depth than at penetration depth which corresponds to radiation energy of $25 \mathrm{kV}$. Thus the tensile residual stress measured on the coating $\mathrm{HIPed}$ at $1200^{\circ} \mathrm{C}$ at an energy of $15 \mathrm{kV}$ is almost equal with that of the as-sprayed coating.

\section{Tribological Testing}

Results of the sliding wear tests are presented in Figs 8 and 9. Friction coefficients which correspond to the tests with steel ball are shown in Fig. 8a. This graph indicates a relatively stable friction during the tests with the exception of the steel ball counterbody on the as-sprayed coating. In this case, the friction coefficient increased sharply shortly after $7 \mathrm{hrs}$, remaning stable for the rest of the test. Thus the friction coefficient of both HIPed coatings after 10hrs was lower by approximately 0.3 than the friction coefficient of the assprayed coating. From Fig. 9a it can be observed that the material loss of the coatings was the highest for the as-sprayed coating, and decreased as the temperature of the HIPing posttreatment increased. The results of the ball mass loss indicate the highest amount of ball material loss for the steel ball in contact with the coating HIPed at $1200^{\circ} \mathrm{C}$.

Friction coefficients of the coating/ceramic ball couples are displayed in Fig. 8b. After the running-in stage the friction coefficient reached an average of 0.85 . A rather unstable stage followed by fluctuations of friction which excedded 0.2 in some cases. However after this stage, as the sliding process progressed, the friction coefficient became more stable. Figure 10 shows interferometer images of the wear scar of the assprayed and HIPed at $850^{\circ} \mathrm{C}$ coatings. Although the wear scar of the HIPed coating is wider than that of the as-sprayed coating, the obvious difference in depth led to the HIPed coating volume loss of approximately half to that of assprayed coating. However, as observed in Fig. 9b, the ceramic ball which slid on the coating HIPed at $850^{\circ} \mathrm{C}$ lost the largest amount of material. On the other hand, surprisingly, the coatings HIPed at $1200^{\circ} \mathrm{C}$ lost almost the same amount of material as the as-sprayed coating while the related silicon nitride ball had approximately the same amount of material loss as the ball which slid on the as-sprayed coating.

\section{Discussion}

In this investigation functionally graded coatings were used to avoid mismatch of mechanical and thermal properties between the substrate and the coating. HIPing conditions were specially designed to avoid cracking of coating during heating and cooling, and to decrease the cost of the process using unencapsulated coating.

Previous studies [e.g. 7] proved that HIPing post-treatment at temperature of $850^{\circ} \mathrm{C}$ for one hour can be successfully applied on un-encapsulated WC based coatings. The present study investigated the effect of HIPing temperature and encapsulation on coating integrity. Thus beside HIPing at $850^{\circ} \mathrm{C}$, the coatings were also $\mathrm{HIPed}$ at $1200^{\circ} \mathrm{C}$ and no encapsulation was used. An analysis of chemical composition on each coating was performed to check the phase transformation which occurred with increasing HIPing temperature. Secondary phases of tungsten carbide $\left(\mathrm{W}_{2} \mathrm{C}\right)$ which are known to form even in the coatings deposited with High Velocity Oxy-Fuel systems became unstable at temperatures above $850^{\circ} \mathrm{C}$. Thus brittle phases such as $\mathrm{W}_{2} \mathrm{C}$ and also metallic tungsten (W) from the as-sprayed coating reacted with nickel and iron from the matrix. The increased intensity of the WC peaks suggests that some secondary phase also converted to $\mathrm{WC}$, conversion facilitated by the carbon which existed in the matrix (Table 1). Hence complex carbides formed contributing to the hardness of the coatings HIPed at $850^{\circ} \mathrm{C}$. The above reactions continued during HIPing at temperatures between $850^{\circ} \mathrm{C}$ and $1200^{\circ} \mathrm{C}$, the number of carbides (WC, $\mathrm{Ni}_{2} \mathrm{~W}_{4} \mathrm{C}, \quad \mathrm{FeW}_{3} \mathrm{C}, \mathrm{Fe}_{3} \mathrm{~W}_{3} \mathrm{C}$ ) increasing. Moreover nickel silicon and nickel borides formed and, consequentely, the coating gained more hardness [9-11].

The above findings are confirmed by the microhardness measurements presented in Fig. 5 - the higher the HIPing temperature the higher the coating microhardness. The difference between the hardness of the two HIPed coatings reached its peak at $250 \mu \mathrm{m}$ from the coating surface. This is due to the fact that the coating structure changed with HIPing temperature. It seems that these changes became more pronounced between $150 \mu \mathrm{m}$ and $250 \mu \mathrm{m}$ as the HIPing temperature increased from $850^{\circ}$ to $1200^{\circ} \mathrm{C}$. As mentioned above, the structure of the coating was partially responsible for the improvement of the properties of the coating. High magnification SEM micrographs showed successive changes which occurred with increasing HIPing temperature. In the coating HIPed at $850^{\circ} \mathrm{C}$, no major change in the shape or size of the tungsten carbide grains was observed compared to the as-sprayed coating. HIPing at $1200^{\circ} \mathrm{C}$ produced noteworthy changes. The tungsten carbide grains transformed to angularshaped grains and the neibouring grains merged to the extent that the boundary between them could not be distinguished.

The increasing of HIPing temperature in conjuction with the pressure of the process was responsible for the enhancement of another process which took place throughout the coating. This is diffusion which provide a metallurgical bonding between layers and also between coating and substrate (Fig. 4). Thus, as seen in Fig. 4d, the interface between the first deposited layer and substrate or second layer disappeared. Diffusion also took place at the interface of individual tungsten carbide grains, leading to an increase in the bonding between lamellae. The results of elastic modulus measurements and also XRD results confirmed the above findings. Thus, the diffusion between neighbour lamellae led to the improvement of their bonding, which was reflected by the substantial increase in the elasticity of the coating HIPed at $850^{\circ} \mathrm{C}$ compared with the as-sprayed coating. The coating elasticity also improved with the temperature of the HIPing process. However the variation of the elastic modulus indicates the anisotropic character of coating HIPed at $1200^{\circ} \mathrm{C}$. Although coating $\mathrm{HIPed}$ at $1200^{\circ} \mathrm{C}$ has higher modulus, the coating treated at $850^{\circ} \mathrm{C}$ has lower modulus gradient, and 


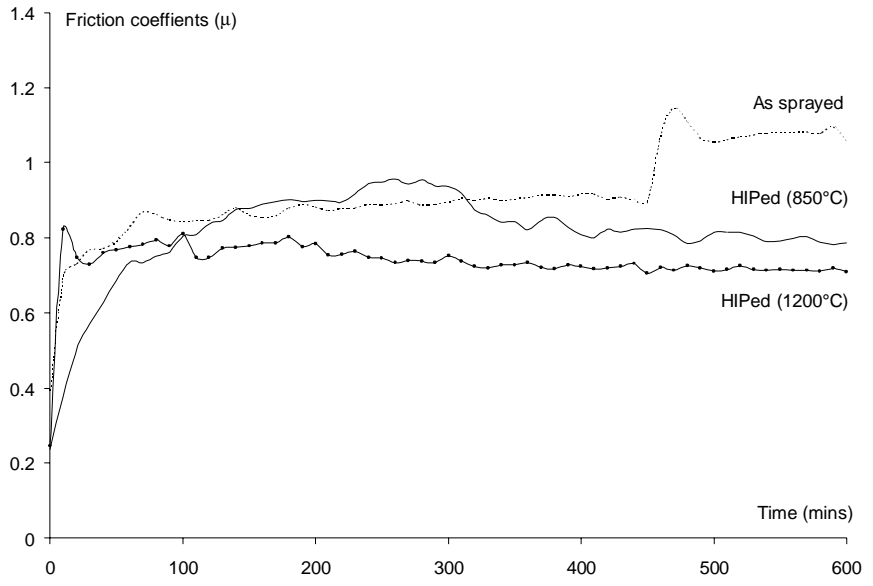

a) Coatings Vs steel balls

Figure 8: Friction coefficients.

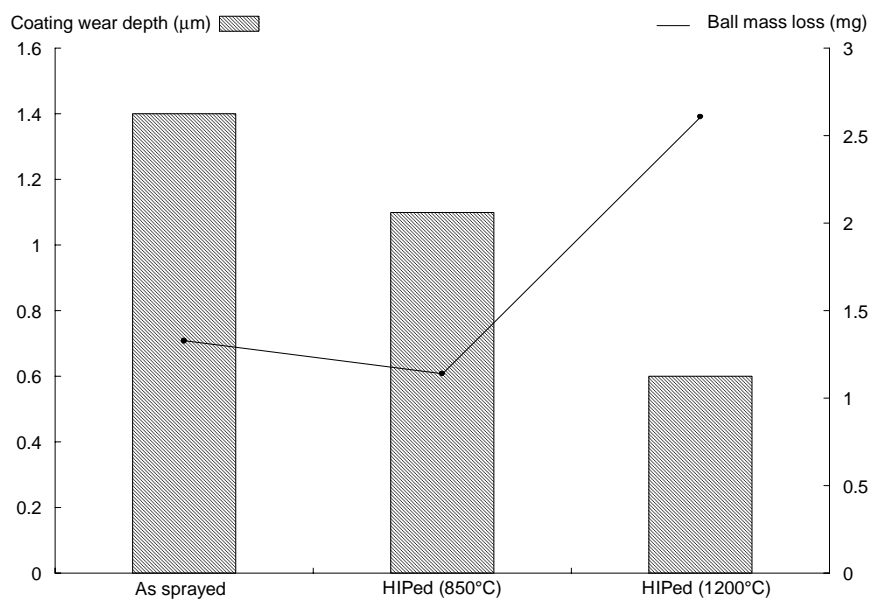

a) Coatings Vs. 440C steel balls

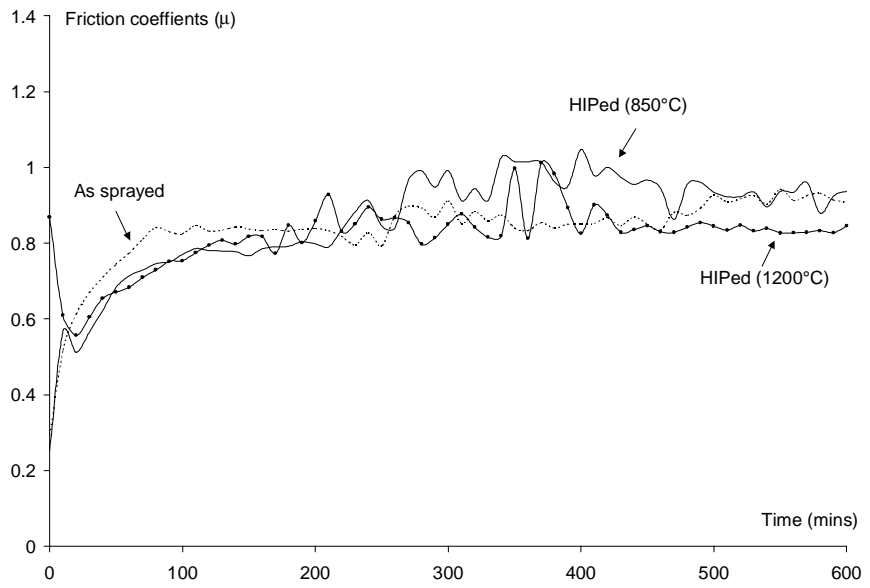

b) Coatings Vs $\mathrm{Si}_{3} \mathrm{~N}_{4}$ balls

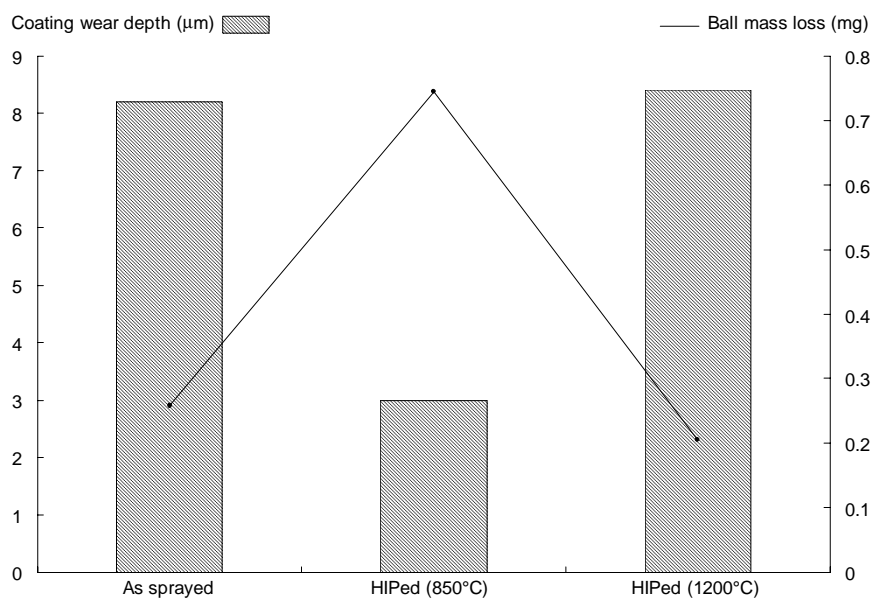

b) Coatings Vs $\mathrm{Si}_{3} \mathrm{~N}_{4}$ balls

Figure 9: Volume $\left(\mathrm{mm}^{3}\right)$ of coating and mass $(\mathrm{mg})$ of ball material removed during the wear tests.

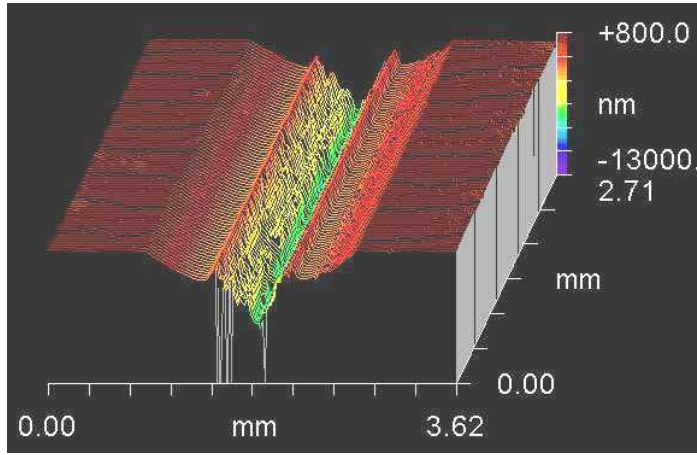

a) as-sprayed coating

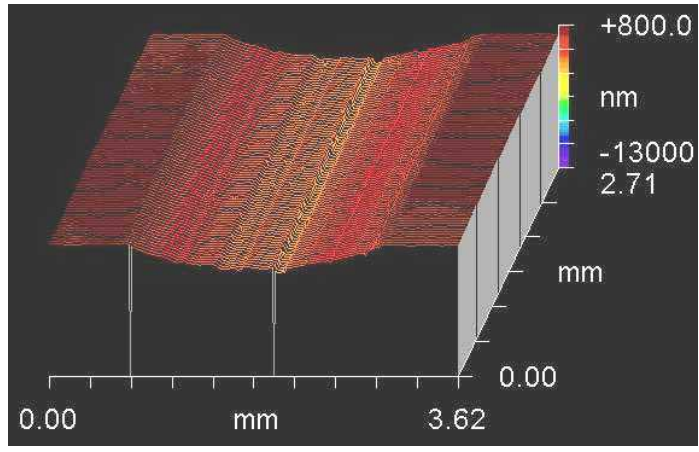

b) coating $\mathrm{HIPed}$ at $850^{\circ} \mathrm{C}$

Figure 10: Sliding wear tracks of as-sprayed and HIPed at $850^{\circ} \mathrm{C}$ coatings. 
hence almost no anisotropy, which is an important finding since the anisotropy is a major problem for thermal spray coatings.

During HIPing at $850^{\circ} \mathrm{C}$, tensile residual stress is built up in the coating and is added to the existent residual stress state. It is believe that this is mainly due to the difference in the coefficient of thermal expansion between the steel substrate and the coatings. Although the effect of this difference is attenuated by the use of funtionally graded coatings, the cooling rate of $8^{\circ} \mathrm{C} / \mathrm{min}$ produced tensile stresses on the coating surface. The above also applies to coatings HIPed at $1200^{\circ} \mathrm{C}$ with the observation that the magnitude of tensile residual stresses which occurred during the HIPing posttreatment is lower than that of the coatings HIPed at $850^{\circ} \mathrm{C}$.

Preliminary sliding wear test results of the coatings sliding against steel balls confirmed that due to succesive increase in the hardness and elastic modulus, the HIPed coatings performed better compared with the as-sprayed coatings. The coatings HIPed at $1200^{\circ} \mathrm{C}$ had the best wear resistance but this corresponded to maximum amount of ball material loss. This is due to the difference which existed in the hardness between the coating HIPed at $1200^{\circ} \mathrm{C}$ and the steel ball, the wear process having the aspect of a machining process.

The results of the tests involving coatings and ceramic balls are rather unexpected as the coating HIPed at $1200^{\circ} \mathrm{C}$ behaved worse than even the as-sprayed coating. However the results are preliminary and further investigations are required to confirm this behaviour.

\section{Conclusions}

Preliminary results indicate that the sliding wear performance of functionally graded $\mathrm{WC}-\mathrm{NiCrBSi}$ coatings can be improved by HIPing post-treatment.

- Results indicate that, increase in HIPing temperature improved the sliding wear resistance of the coating. However in the particular case of contact between thecoatings and a hard counterbody e.g. ceramic ball, preliminary results showed that intermediate temperature of around $850^{\circ} \mathrm{C}$ provided the best sliding wear resistance.

- Microstructural investigations show that considerable diffusion at the interface of coating layers take place, especially at higher temperatures.

- Changes in coatings Young`s modulus and hardness are indicative of the microstructural changes seen in XRD pattern.

- This investigation confirms that uncapsulated HIPing can be successfully applied to post treat thermal spray coatings by appropriate design of functionally graded coatings and HIPing conditions.

\section{Acknowledgements}

Authors would like to thank Dr Susan Davies at Bodycote HIP Ltd., UK for her support during the HIPing post-treatment. Financial support of EPSRC (Grant Number GR/R45284) and Nuffield Foundation (Grant Number NAL/00294/G) is also gratefully acknowledged.

\section{References}

1. H. Ito, R. Nakamura, R. Shiroyoma, M. Sasaki, Posttreatment of plasma sprayed WC-Co coatings by Hot Isostatic Pressing, pp. 233-238 of Thermal Spray Research and Applications, Proceedings of the 3rd National Thermal Spray Conference, Thomas F. Bernecki, Ed., ASM International, ASIN: 0871703920, 1990.

2. H. Kuribayashi, K. Suganuma, Y. Miyamoto, M. Koizumi, Effects of HIP treatment on plasma-sprayed ceramic coating onto stainless steel, pp. 1306-1310 of Am. Ceram. Soc. Bull. 65, 1986.

3. K.A. Khor, N.L. Loh, Hot Isostatic Pressing of plasma sprayed ceramic coatings, pp. 804-809 of CeramicsAdding the value: Proceedings of the Third Int. Thermal Spray Conference, 1992.

4. K.A. Khor, Y. Murakoshi, M. Takahashi, T. Sano, Plasma spraying of titanium aluminide coatings: Process parameters and microstructure, pp. 413-419 of Journal of Materials Processing Technology 48, 1995.

5. K.A. Khor, Y.W. Gu, Hot Isostatic Pressing of plasma sprayed yttria-stabilized zirconia, pp. 263-268 of Materials Letters 34, 1998.

6. H.C. Chen, E. Pfender, J. Heberlein, Structural changes in plasma-sprayed $\mathrm{ZrO} 2$ coatings after hot isostatic pressing, pp. 227-235 of Thin Solid Films 293, 1997.

7. V. Stoica, R. Ahmed, S. Tobe, Wear of hot isostatic pressed (HIPed) thermal spray cermet coatings, pp. 930937 of Thermal Spray: Surface Engineering via Applied Research, C.C. Berndt, Ed, ASM International, ISBN: 087170-680-6, 2002.

8. M. Buchmann, M. Escribano, R. Gadow, G. Burkle et al., On the elastic mechanical properties of thermally sprayed coatings, pp. 598-605, op. cit. ref. 7

9. Z. Ding, H. Zhao, J. Wang, Effect of WC content on the wear resistance of Ni-base alloy spray fusing overlays, pp. 1089-1092 of Thermal Spray 2001: New Surface for a New Millennium, C.C. Berndt, K.A. Khor, E.F. Lugscheider, Ed., ASM International, ISBN: 0871707373, 2001

10. S.C. Modi, E. Calla, Structure and properties of HVOF sprayed NiCrBSi coatings, pp. 281-284, op. cit. ref. 9.

11. O. Knotek, H. Reimann, P. Lohage, Reactions between Ni$\mathrm{Cr}-\mathrm{B}-\mathrm{Si}$ matrixes and carbide additives in coatings during fusion treatment, pp. 361-367 of Thin Solid Films 83, 1981 